\title{
Enablers and Barriers to Respectful Maternity Care in Low and Middle-Income Countries: A Literature Review of Qualitative Research
}

\author{
Florence Mgawadere', Umar Shuaibu ${ }^{2 *}$ \\ ${ }^{1}$ Centre for Maternal and Newborn Health, Liverpool School of Tropical Medicine, Pembroke Place, Liverpool, UK \\ ${ }^{2}$ Liverpool School of Tropical Medicine, Pembroke Place, Liverpool, UK \\ Email: *shuaibumakama@gmail.com
}

How to cite this paper: Mgawadere, F. and Shuaibu, U. (2021) Enablers and Barriers to Respectful Maternity Care in Low and Middle-Income Countries: A Literature Review of Qualitative Research. International Journal of Clinical Medicine, 12, 224-249.

https://doi.org/10.4236/ijcm.2021.125021

Received: April 21, 2021

Accepted: May 25, 2021

Published: May 28, 2021

Copyright $\odot 2021$ by author(s) and Scientific Research Publishing Inc. This work is licensed under the Creative Commons Attribution International License (CC BY 4.0).

http://creativecommons.org/licenses/by/4.0/

\begin{abstract}
Background: Low and Middle-Income Countries (LMIC) account for 94\% of maternal deaths annually. Interventions to reduce these deaths include; access to Emergency Obstetric Care (EmOC) and Skilled Birth Attendant (SBA) at childbirth. However, evidence indicates increasing access to EmOC, and SBA only does not translate into positive maternal and newborn outcome due to disrespectful care faced by women during labour. World Health Organization (WHO) guidelines emphasize on positive birth experience through Respectful Maternity Care (RMC). Therefore, this review aims to explore enablers and barriers to respectful maternity care in low and middle-income countries. Methods: We conducted an exhaustive literature search for studies that reported on enablers and barriers to respectful maternity care. Qualitative studies done in low and middle-income countries, published in English Language from the year 2000 to June 2020 were included in this study. Articles were screened by two researchers for eligibility and critical appraisal skills programme checklist was used to appraise the quality. The themes and quotes from the studies were extracted and synthesized using thematic synthesis. Results: The search strategy generated 14,190 articles and 54 studies met the inclusion criteria. Two main themes: interpersonal relationship and support, and privacy and confidential care were reported as both enablers and barriers to respectful maternity care. Strategies to promote RMC were: health education to pregnant women on care expected during labour, good communication between maternity staff and women, capacity building of staff on RMC and staff motivation. Conclusion: Respectful maternity care plays a big role in promoting health-seeking behaviours among pregnant women. However, women experience barriers ranging from provider behaviour, work environment and health system challenges. Ensuring a dignified and respectful
\end{abstract}


working environment could contribute to an increase in health seeking-behaviours and consequently reduction of maternal mortality.

\section{Keywords}

Respectful Maternity Care, Low and Middle-Income Countries

\section{Introduction}

Many women and children continue to die due to pregnancy-related causes [1]. The global maternal mortality estimates for 2017 indicate about 295,000 maternal deaths and approximately 810 daily deaths from preventable causes related to pregnancy and delivery, about $94 \%$ of these deaths occurred in low-income settings where women still do not have maternal healthcare they need [1] [2]. Approximately 5.3 million under five children died in 2018, about $47 \%$ of these deaths were newborns who died of preventable causes [3].

The causes of maternal mortality are grouped into direct and indirect, the direct causes include: obstetric haemorrhage, hypertensive disorders of pregnancy, sepsis, abortions, prolonged obstructed labour. The indirect causes include: malaria in pregnancy, anaemia, HIV and chronic medical conditions in pregnancy [4]. Haemorrhage is the commonest and can cause death to pregnant women within a few hours if unattended [2]. The causes of newborn death include: birth asphyxia, preterm birth complications, prematurity among others [3].

Interventions to reduce maternal and newborn deaths are known and include: access to Emergency Obstetric Care (EmOC) and Skilled Birth Attendant (SBA) at childbirth for timely interventions [5]. However, evidence indicates increasing access to EmOC, and SBA only does not translate into positive maternal and newborn outcome [6]. World Health Organization (WHO) guidelines emphasize on positive birth experience through Respectful Maternity Care (RMC) which promote healthcare-seeking behaviour and access to EmOC and SBA among pregnant women and can prevent maternal mortality [7]. This implies providing quality maternal care does not only require adequate equipment and professional skills but positive attitudes from health workers to promote optimal interventions in maternity care [8]. There is increasing evidence indicating many women in Low and Middle-Income Countries (LMIC) are deterred from facility-based delivery due to dehumanized care by healthcare providers [9], hence increasing attentions and calls towards good relationship between pregnant women and healthcare providers through promoting respectful maternity care [9]. Despite global attention on how women were treated with disrespect during labour, there are limited studies that have explored circumstances causing poor care and strategies to mitigate it [10] [11] [12]. Therefore, this study synthesized the existing literature on enablers and barriers to RMC as well as summarized strategies that would enhance respectful maternity care in low and mid- 
dle-income countries which may help to improve maternity healthcare utilization and decrease maternal mortality.

\section{Conceptual Framework}

In Figure 1, pregnant women's decision to seek healthcare services start by looking at the health systems environment and structure of the service provision. Their expectations, previous experience from self or other women, perceived quality and satisfaction of care during antenatal and delivery compared with the outcome of the whole process influences their decision to seek care. Positive experience of care associated with respect attracts women for future facility-based care which can improve maternal and neonatal outcome as shown in an adapted framework for measuring RMC outcomes.

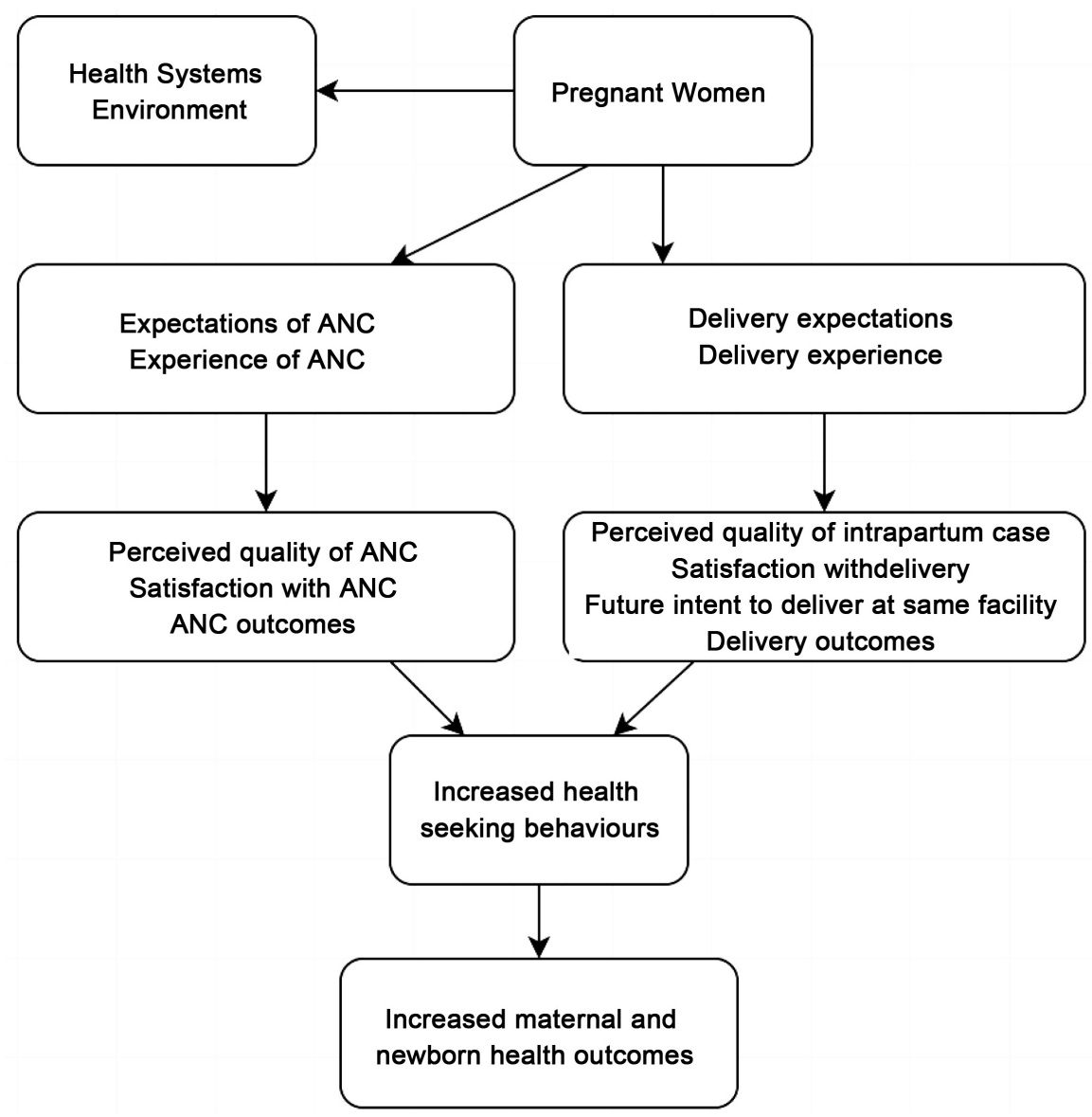

Figure 1. Conceptual framework for measuring RMC outcomes to maternal and newborn health as adapted from previous study [13]. ANC: Antenatal Care, RMC: Respectful Maternity Care.

\section{Study Methodology}

\subsection{Study Design}

This study is a literature review of qualitative studies conducted in low and middle-income countries that identified and explained the enablers and barriers to 
respectful maternity care, and summarized strategies that would enhance respectful maternity care.

\subsection{Justification for Choice of Design}

Literature review as a stand-alone research method is a more or less systematic process of collecting, appraising and synthesizing existing literature to summarize the findings of all research relating to the objectives of the study [14]. Reviewing the literature would provide enhance understanding of the area of interest, provide current evidence that enhance transferability, improve clinical outcome and evidence-based decision-making processes as well as avoiding unnecessary duplication of research work [15] [16].

In respect to the topic, since year 2000 following Millennium Development Goals (MDGs), that is when most countries started investing in maternal health and encouragement for facility-based delivery [17], and several calls by governmental and non-governmental organization to provide humanized care to pregnant women during labour and delivery, yet studies regarding perception and experience of women during facility-based delivery as well as the practices of skilled health professionals toward humanization of birth care are limited [10]. Also, several studies indicate lack of public health research that identified both enablers and barriers to RMC [18], while other studies indicate previous reviews have identified disrespectful care not limited to individual alone but reflects systematic failures and deeply rooted providers attitudes and beliefs [9]. Therefore, literature review is suited for this study to synthesize and bring together current evidences on enablers and barriers to RMC and summarize strategies that would enhance RMC.

A qualitative study was suited to identify studies where pregnant women were asked and explored experiences they go through during labour and delivery at health facility by their attending health personnel, questions explored by healthcare attendants and other stakeholders on why certain actions or attitude were exhibited to pregnant women [19]. The enablers or barriers to respectful maternity care may arise from behavious and actions exhibited by healthcare workers such as physical abuse, non-consented care, non-confidential care, non-dignified care, discrimination, abandonment of patient during care and detention of patient in healthcare facilities [20]. Therefore, these actions or behaviours can be best explained or explored by qualitative method because, is suitable for understanding and describing the perception and views of women experiencing various forms of abuse during labour [21], hence qualitative approach better for this study to know how and why certain actions or behaviours are exhibited and summarize strategies that would enhance RMC.

\subsection{Literature Searching}

The literature was searched using the following databases; MEDLINE, CINAHL and Global health. The three databases focus on general medicine, nurs- 
ing/midwifery and international public health respectively. They provide access to good range of literature type and journals. Using multiple database combination (the three databases) provide optimal searches and guarantee adequate and efficient coverage of available studies during literature review [22]. The topic for the research is also related to maternal health and CINAHL is a good database for most current Nursing and Allied health literature especially maternal and child health [23].

Additional search from the web pages of relevant international organization such as the World Health Organization (WHO), United Nations Children Fund (UNICEF) and World Bank was done.

All references of the retrieved papers and reports were also checked to identify any relevant literature on the same topic.

The literature searching was done via an access through the Liverpool School of Tropical Medicine search engine DISCOVER. The process was performed from $29^{\text {th }}$ May 2020 to $26^{\text {th }}$ June 2020 . The process followed systematic approach during literature searching from title, abstract and full text search [24] and the search history of included and excluded studies were documented using PRISMA flowchart [25].

\subsection{Quality Assessment of the Studies}

The quality of this study was assessed using adopted critical appraisal skill programme checklist (CASP) [26]. It has ten (10) questions which are designed systematically and the response to the questions can be Yes, No or Can't tell with the total score of ten [26] [27]. Studies with score of at least 8 are regarded as high quality, 5 to 7 as medium quality and score of less than 5 are regarded as low quality studies [28].

\subsection{Data Analysis}

Thematic synthesis was used to analyze data in this study, a method mainly used to analyze data in qualitative research [29]. This method is frequently used for systematic or literature reviews in health and social science literature to answer qualitative research questions, it also identifies meaning of social phenomena the way the participants experience it or perceive it [19] [30].

\subsection{Ethical Consideration}

This study is a literature review that used published studies and there is no direct or indirect contact with a human subject. However, all included research papers were carefully screened for ethical approval and adherence with principles of research ethics.

\section{Results}

\subsection{Results of Literature Search}

The search from the three databases yielded a total of 14,190 articles (MEDLINE $=$ 
1418, CINAHL $=1490$, Global health $=11282)$ and 28 materials were identified from the web page of WHO-Reproductive Health Library (WHO-RHL). After removing the duplicates electronically using Endnote citation software, a total of 12,772 articles remained. After screening the titles and abstracts, 58 studies were met the criteria. Following full texts screening, a total of 54 studies were selected and included in the review. A PRISMA flowchart, Figure 2 summarizes the searched history of included and excluded studies with reasons.

\subsection{Study Description}

\subsubsection{Geographical Distribution}

This study included 54 studies done in 19 low and middle-income countries in Asia and Africa. The majority of the included studies (48) were conducted in Africa and the remaining six (6) studies in Asia. Almost half (22) of the included studies were conducted in East Africa with Tanzania having the highest number of studies included in this review (eight studies). Also included in the review is one multi-country study comprising of Southern and East African countries (Ethiopia, Kenya, Tanzania, Rwanda and Madagascar). With regard to the settings, 13 studies were conducted in rural settings, 13 studies also in urban and 28 in mixed/peri-urban settings.
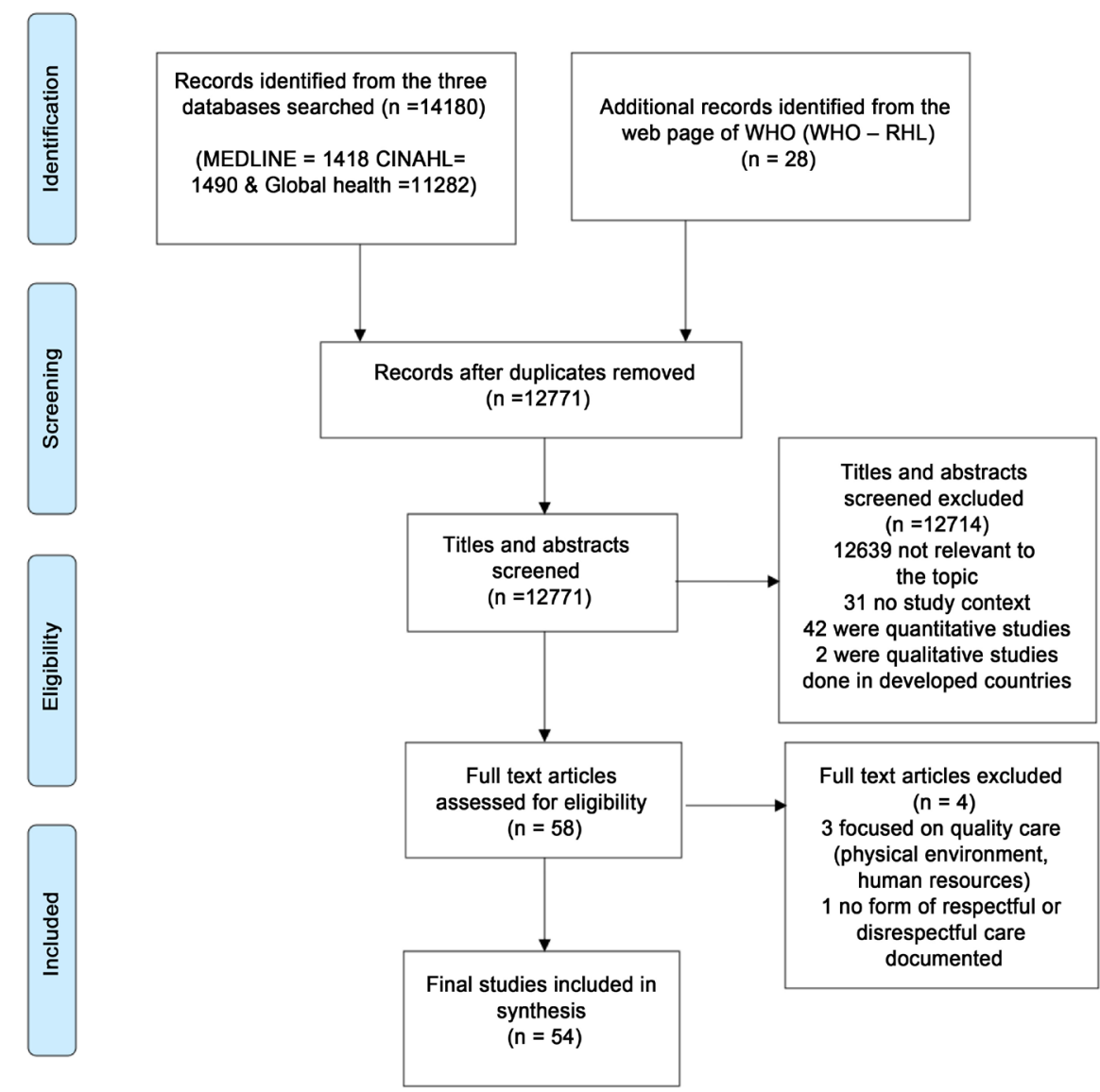

Figure 2. PRISMA flowchart showing process of selecting the studies [25]. 


\subsubsection{Description of Themes}

The synthesis of findings from the included studies generated themes and sub-themes. Two themes and five sub-themes were identified relating to factors that enhance respectful maternity care and two themes with five sub-themes also related to factors that inhibit RMC. The strategies that would facilitate RMC were represented in four main areas.

Factors that enhance respectful maternity care in low and middle-income countries.

1) Good interpersonal relationship and support

There were five sub-themes under this major theme;

\section{a) Good reception}

Good reception and welcome of pregnant women by the healthcare staff was mentioned by women in six studies. Women reported that good reception upon arrival provides comfort and assures them of supportive and respectful care during delivery [31] [32] [33] [34] [35]. Direct observations of labour in the delivery room carried out by society of Obstetricians and Gynaecologists of Burkina Faso showed good reception of the pregnant women in the delivery room promoted satisfaction throughout the delivery and was expected to encourage women to go for hospital-based delivery in future pregnancy [36].

"As for me I feel relaxed when a midwife greets me upon my arrival. Just a greeting and a smile assures me of good care" [34].

\section{b) Information provision}

Information provision during labour and delivery was mentioned in majority of the studies but four were related to this objective. Women reported that appropriate information on the progress of labour and involvement in the care decision provides pain relief and promotes satisfaction throughout delivery [31] [33] [37].

"The nurses/midwives always tell me that my cervix has opened to this level (example four centimeters) and others after assessment.... Interestingly she interpreted my laboratory results for me, truly I thought she was a medical doctor because she explained herself very well to my understanding" [33].

In another study, in response to the questions by a woman in labour room on how to adopt a certain position to relief her pain, the midwife responded well to her questions with associated respect [38].

"When I was experiencing severe pain, she told me to lie on the side, sit or adopt any position and I feel comfortable" [38].

\section{c) Promptness of care}

Two studies mentioned how quick intervention in care plays a role in saving lives and at the same time lead to respect and satisfaction to women and can promote facility-based delivery [39] [40].

"When I arrived, I was complete, they delivered me immediately but had some bleeding of which they stopped. One hour later, I went to the bathroom and fainted from there, they promptly attended to me, gave me IV fluids and did 
some suturing down there. If it had been before I would not have survived" [40].

d) Dignified care

Care of women devoid of physical and verbal abuse was mentioned in 20 studies. Gentility of healthcare staff on how they carry out examination of pregnant women during labour was narrated by women to convey respect and feeling of satisfaction [37] [41] [42].

"she was very gentle with me. She didn't rough handle me." [41].

Some women expressed that midwives can comfort them during delivery by encouragement and support devoid of verbal or physical abuse. It was also narrated that the dignified care received can promote them and others to seek care in the same facility in subsequent pregnancies [32] [34] [38] [43] [44] [45] [46].

"Some nurses they comfort you, they direct you how to push, and they sing a song for you. (...) They comfort you in a good way. Let's pray to God and you are going to deliver safely. When in the end you deliver safely, next time you will be motivated to come because the nurse was very nice, she can help you" [32].

Women reported to have crossed borders to seek respectful and friendly services irrespective of the cost [21].

"As I live by the border, I prefer going to hospital (over the border in a neighbouring country) although I need to spend more money on transport, food and family companion because health professionals there are friendly" [21].

Women considered provision of basic materials such as sanitary pad and other supportive material during labour and delivery as respect and encouraging to facility-based delivery [31] [39] [47] [48] [49].

"when I delivered, I was given a cloth to use as a sanitary pad. The nurse was not disgusted that I was soiled, she wiped me clean. The cloth that was underneath was removed. Therefore I see that I was properly cared for" [31].

Women narrated that they were referred by their fellow women due to previous supportive and dignified care received [50] [51] and one woman narrated what attracted her to deliver in the hospital was the dignified care received by her friend on accompanying her to the same hospital [52].

"There was a friend of mine who was pregnant and requested me to escort her during the time of delivery. She delivered from (here). The way staff treated her attracted me to deliver from there" [52].

\section{e) Psychological support}

Three studies indicated that women expressed their satisfaction with the care they received due to good psychological support. Women narrated that the companionship received during labour and delivery by midwives as they were not left alone, they were supported which reduced the stress of labour [42] [43] [47].

"There were three of them (midwives) sitting around my bed. They were talking to me. Yes, they were a companion to me" [42].

\section{2) Privacy and confidential care}

Five studies mentioned the role of privacy and confidential care in promoting 
respect and improving maternal healthcare services. Women said provision of physical barrier in the labour room secured privacy to them during labour and provide comfort, respect and feeling of good care throughout delivery [31] [45].

"The curtains were drawn so that people passing by would not see what was happening inside" [31].

In two studies, women narrated that limiting the number of people in the labour room make them to feel comfortable and respected, also provides confident and satisfaction during delivery [48] [50].

"It was just the nurse and I (in the delivering room). I would like to be alone with the nurse. I think that is proper" [48].

Many stressful and shameful events may occur during labour. Therefore, women patronized facilities that provide respectful and confidential care. In these studies, women stressed how the healthcare staff keep secrete of what happened to them during delivery which was associated with respect and satisfaction [31] [33] [50].

"During my delivery a lot of things happened. It got to a time I messed myself up. The midwives just helped me as if I was their daughter. If she was someone else, she would be saying I am the one who delivered her, and I messed myself up. With this I see that, the midwives kept confidentiality. She did not say anything to anyone" [33].

Factors that inhibit respectful maternity care in low and middle-income countries.

1) Lack of interpersonal relationship and support

There were five sub-themes under this major theme;

\section{a) Poor communication}

Poor communication between healthcare providers and women was mentioned in majority of the studies (32/54). Many women described their delivery experiences as non-supportive, disrespect associated with embarrassing statements, including insults from healthcare staff [32] [41] [44] [53] [54] [55] [56].

"The health workers are mistreating us. For instance when a patient has called for help they ignore by saying I was not there when you were having sex with your husband" [53].

Women also described the care they received from the doctors and midwives as unfriendly associated with shouting and disrespect [21] [31] [33] [35] [37] [38] [42] [46] [50] [52] [57]-[63].

"I messed on the floor, with the blood because I was pushing (short laugh) she (nurse) was there in the office, now I was messing and she told me um, um, 'Go and get a mop there and make your mess clean'" [58].

Lack of information or involvement in the decision during the entire labour and delivery in healthcare facility was considered as lack of respect in the following studies [31] [39] [48] [49] [58].

"They did not tell me anything, I just saw the vehicle ready and they told me you are going to ( $X$ referral hospital) because you are going for an operation" 
[39].

Denied chances to talk to healthcare personnel was disturbing and disrespectful to women in these studies [64] [65].

"They will not even give you chance to talk. They will just shout at you, but you have nothing to say or to do than to manage" [64].

Some women expressed their decision not to seek facility delivery, prefer to deliver at home due to previous disrespect and lack of good communication by healthcare providers in healthcare facilities [21] [48] [55] [57] [61] [64] [66] [67] [68].

"There is one mother who I have spoken with quite often, she says she delivered by herself. She said she called the nurse to come, but the nurse said, 'Don't disturb me so much.' So, the mother stayed and delivered by herself. ...the mother could not go back to the hospital next time" [57].

\section{b) Non-consented care}

Non-consented care was mentioned in four studies. Women express concern over lack of respect on service provision due to inability of healthcare providers to seek permission before carrying out any procedure [45] [50], women reported that sometimes students examine them without any communication [63]. On the other hand, the providers reported asking for consent for any procedure may not be necessary despite disrespect and violation of the right of women as narrated in one study [69].

“... To be honest we are not always asking for consent before examination. I don't think taking consent for every medical procedure is helpful despite the scientific recommendation" [69].

\section{c) Stigma and discrimination}

Stigma and discrimination faced by women during delivery were mentioned in nine studies. Healthcare staff stated that they got angered by conducting delivery of non-educated women and hence impede RMC [59]. Women expressed that they were being discriminated and faced disrespectful care due to poor financial status [32] [44] [46] [57] [61] [70].

"If you don't have money, they look at you as if you are not there. They leave you like that. So, we prepare. As you know it's just about money so we prepare and then go" [57].

Women also stated that they faced disrespect and discrimination based on country of origin [63]. In another study, health workers narrated unequal treatment due to diseases such as HIV [69].

"For us who are from outside the country, they say 'you Zimbabweans are burdensome, you are tiresome, and you give birth a lot'. They treat us bad" [63].

d) Physical abuse

Various forms of physical abuse were expressed by women during delivery or explained by midwives and an observer in 13 studies. The physical abuse faced by women during labour such as beating is common, associated with disrespect as mentioned in these studies, women narrated that they had to forcefully 
co-operate to avoid been beaten [45] [50] [56] [57] [59] [60].

"... They beat me enough... Yes, they beat me hard, so hard that at the end of the whole thing... I found out that if I don't push, I may end up..." [59].

Healthcare providers had admitted that the physical abuse commonly experienced by pregnant women were associated with disrespect but assumed as a form of discipline to non-cooperative women [37] [59] [69] [71] [72].

"When we are doing an episiotomy, the mother may want to stand and try to leave the room, in such cases, we may kick the women by scissor..." [69].

Three observational studies also indicated how women were physically assaulted and treated with disrespect during labour [73] [74] [75].

"Patient came in second stage of labour pushing now and then, delivered, placenta had difficulties to remove as the mother was not tolerant, the nurse slapped the women" [73].

e) Poor psychological support

Poor psychological support during maternity care by healthcare providers was mentioned in twelve studies. Women narrated that they feel scared and worried with lack of respect in health facility during delivery because their relation was not allowed to be with them to offered psychological support [21] [45] [57] [58] [67] [76]. Some women express lack of respect with repeated virginal examinations which is painful and affect them psychologically [77].

"The care providers hurt us psychologically. They came and did vaginal examinations repeatedly as simple as anything but it is a big trauma to us" [77].

Some women stated that they were left unattended due to failure to follow instructions, the care received were also associated with lack of rapport by healthcare staff at various stage of delivery processes [45] [57] [60] [61] [63] [73] [77] [78].

"... they abandoned me because I could not go up on the delivery table..." [60].

\section{2) Lack of privacy and confidential care}

Another theme that emerged is lack of privacy and confidential care during maternity care services.

Lack of privacy during care is associated with lack of respect and was mentioned in ten studies. Women stated that the care they received compromised their privacy due to lack of partition and protective cover in the delivery rooms as they were seen by people passing by [33] [34] [49] [50] [59] [61] [69] [79].

"Even when I was giving birth maintenance people were passing by, they were looking at me and there were no curtains. I felt embarrassed" [34].

In two studies, it was observed that some women were left uncovered and were seen necked compromising their privacy [40] [62].

"The nurse left the woman uncovered when she delivered; also the door was open to the extent that when other people were passing they could see her" [62].

Lack of confidential care to women was mentioned in three studies. Women felt disrespected as their secrecy were discussed with other people even in their 
presence as narrated by maternity healthcare staff [44] [45] [58].

“... I can work on you, then come and discuss you with another person even in your earshot. There are no ethics..." [44].

Strategies that would facilitate respectful maternity care in low and middle-income countries.

The strategies that would facilitate RMC were summarized as suggestions to the management and staff of maternity ward from the respondents. Twenty (20) studies reported some strategies to promote respect.

1) Health education to pregnant women

Health education to women during antenatal is an important strategy that would enhance RMC, it was mentioned in seven studies. To have respectful care, women stated that healthcare staff in the maternity ward should provide them with basic health education during antenatal on care expected during labour so that they get prepared [41]. In another study, women narrated that they should be given necessary health advices during labour to ease their suffering [65].

"They are supposed to tell you what to expect, what to do when the time come. You know those few things, those few basics" [41].

Healthcare staff narrated that for them to provide RMC, the rural un-educated pregnant women should be provided with the required information during antenatal visit, also involve them in care decisions as it eases stress of explanations during delivery and subsequent care [35] [42] [50] [51] [79].

"As most clients come from the rural community, they may not be willing to respond to the questions they were asked. They have to be educated. The clients lack education and need to be well counselled to be compliant with what providers tell them to do." [50].

\section{2) Good communication}

Good communication ensures RMC and was mentioned as a strategy that would enhance respectful care in eight studies. Maternity healthcare staff stated that welcoming women during delivery with good communication create respect and comfort throughout labour [80].

"When mother arrives, we should kindly welcome her and call her name in a respectful manner. In this way, she would feel comfortable." [80].

Healthcare providers also narrated that good communication with respect to pregnant women during delivery make them relax and provide the required information needed for quality care [37] [50] [52] [81] [82].

"Good communication helps the mother to open up. If she is having a serious condition or may be in the private parts when you are not a good communicator the mother may hide that information." [52].

In two studies, maternity staff stated that respectful and quality care is provided when healthcare worker communicate without shouting to the clients [54] [82]. in another study, one maternity healthcare staff narrated that if client does not want something to be done during the delivery, instead of abusing the women, the provider can document what happened [74]. 
"To me good quality care with respect is when a health worker talks to you well without shouting." [54].

\section{3) Capacity building of maternity healthcare staff on RMC}

Four studies mentioned the role of staff training for successful provision of RMC. Two of the studies, indicated the need of the staff in the maternity ward to be trained especially the heads of the maternity ward for their leadership role and responsibility for improving maternity ward condition, psychological training should also be included on how to handle hostile patient [8] [44] [75]. One maternity care provider in one study narrated how she appreciated and intent to use the knowledge acquired following the training received on how to support and provide RMC to women during delivery [68].

"(training on) how to handle patients who are hostile and who cannot cooperate and ... how you build confidence in patients so that they become free and open up." [75].

\section{4) Staff motivation}

Motivation to healthcare providers was mentioned in two studies and can help reduce disrespect and abuse during maternity care. Management staff narrated how good working environment and financial or other forms of commendation to maternity staff performing good quality services to clients would motivate them to provide better and more services [8]. Sometimes, good feedback from the community also motivates the healthcare providers to perform and deliver effective care to the clients [81].

"I feel motivated because of the feedback that I get from people yeah cos (because) I could meet some people may be a mother and her baby... she will come to me and say this is your child you delivered me during that time so I feel like wow this is great' [81].

\section{Discussion}

The main objective of this review was to summarize existing literature on facilitators or enablers and barriers to respectful maternity care, and also to summarize strategies that would enhance RMC. Two themes and five sub-themes were identified relating to both factors that enhance respectful maternity care and factors that inhibit RMC. The enablers to RMC reported include; good interpersonal relationship and support between women and maternity staff (good reception, information provision, promptness of care, dignified care and psychological support), and privacy and confidential care. On the other hand, the barriers to RMC include; lack of interpersonal relationship and support (poor communication, non-consented care, stigma and discrimination, physical abuse, poor psychological support), and lack of privacy and confidential care. Health education, staff capacity building on RMC, staff motivation and good communication between maternity staff and women emerged as strategies to promote RMC. To our knowledge, this review is the first qualitative synthesis that has looked into both factors that enhance and inhibit RMC including a summary of suggested 
strategies that would enhance RMC in low and middle-income countries. The findings of this research have provided insight into opportunities which can possibly be used to enable governmental, non-governmental organization and other policy makers to make informed decisions to improve RMC and increase facility-based delivery and subsequently contribute to reduction in maternal mortality.

\section{1) Factors that enhance respectful maternity care}

Good interpersonal relationship and support were found to be an important factor that enhances RMC in this review. Good reception, a greeting and communication during care of pregnant women was reported to enhance good relationship and support of women by maternity healthcare workers. Women's get assured of good supportive, quality and respectful care during delivery by the first positive impression upon arrival at healthcare facility. This finding is similar to another review of literature done in developing countries where warm welcome with good communication led to maternal satisfaction during delivery [83].

Adequate information provision regarding progress of labour also created a good interpersonal relationship between women and maternity healthcare staff. This review found that information provided to women about pregnancy, labour and delivery promoted the future intention to seek facility-based care. This finding is in support of our conceptual framework which stipulate that positive experience of care associated with respect attract women for future care thereby improving maternal and neonatal outcomes. Similarly, a study done in Netherlands found good information provision during pregnancy improved maternity care services [84]. World Health Organization (WHO) also emphasizes the need to provide pregnant women with simple and culturally effective information and respectful care to promote health seeking behaviour and positive maternal outcomes [85].

The findings of this review also revealed that women regard prompt and quick interventions during care as a respect, it creates positive feeling of being treated well in healthcare facility. In one of the studies, one women alluded satisfaction with prompt care after fainting following per virginal bleeding [40]. Another study on quality maternal care indicated prompt intervention through quality care prevents bleeding during delivery thereby leading to maternal satisfaction with the care received [86].

Dignified care to women during labour and delivery is a WHO recommendation to ensure respect to women [87]. In this review, it was found that an enabling environment for women to open up and discuss their maternity care challenges with healthcare providers encouraged women to refer other women and seek similar healthcare during future pregnancies. Some women narrated crossing to country borders to seek dignified care in this review [21]. This finding is in agreement with another study on the determinants of women's satisfaction with maternal healthcare from developing countries where dignified care by 
midwives was found to satisfy women and attracted more women to come for skilled care [83]. Also, similar to a review of the effectiveness of respectful care policies for women using routine intrapartum services where it indicated fewer accounts of non-dignified care to women during labour [88].

Care associated with privacy and confidentiality was another factor that can enhance RMC found in this review. Provision of adequate protective cover at doors such as curtains, maintaining confidentiality and limiting the number of people in the labour room especially non-professional staff promoted a feeling of respect and increased confidence among women. This finding is consistent with a study on drivers of maternity care in high income countries where privacy and confidential care satisfied women [89].

\section{2) Factors that inhibit respectful maternity care}

Lack of interpersonal relationship and support was found to be a factor that impede RMC. Poor communication characterizes by shouting, insult hinders women's decision to seek care in subsequent facility-based care. Poor communication associated with lack of involvement in care was classified as barrier to provision of RMC. The finding of this review is in line with our conceptual framework where poor experience and satisfaction from poor quality care will negatively affect women health seeking behaviour in subsequent pregnancies and may lead to poor maternal and newborn outcomes. Another study that explored childbirth practices and challenges for humanization of care done in two public hospitals in Brazil support our finding that poor communication to pregnant women is a barrier to RMC [90].

A study done in Peru found non-consented care during maternity care affected care decision of women [91]. Similarly, in this study non-consented care was considered as disrespect among women. Women were not happy with healthcare staff and students who did not seek permission before doing any procedure. Such practice hindered the co-operation of women throughout delivery and future care. It was worrisome that some healthcare providers who are expected to respect women stated that seeking permission to carry out procedure to women may not be necessary. This may be considered as gross violation of women right according to RMC charter [92] [93].

Reported stigma and discrimination to women during maternity care was found to affect RMC in this review. The stigma and discrimination were associated with poor education of women, poverty, differences in country of origin and due to disease such as HIV. The finding is consistent with a study on silent burden of stigmatization among Germanic ethnic group (Dutch women) in the Netherlands which found that women with low socio-economic status from a foreign country were discriminated [94]. In addition, our finding conforms with finding of secondary analysis on mistreatment of women during childbirth in healthcare facilities in developed countries where discrimination based on sociodemographic characteristics and medical conditions were found to impede RMC [95]. 
Physical abuse faced by women during care was found to impede RMC in this review. Many studies reported women were beaten due to lack of cooperation during painful procedures such as episiotomy without anaesthesia. This affected women's decision to visit same hospital during subsequent pregnancies. This finding conforms with another review of disrespect and abuse of women during childbirth in Nigeria where restraining of women during labour, beating and episiotomy without anesthesia were common practices in maternity ward and was found to impede RMC [18]. Also, similar to a study done in Brazil. Women who were physically and verbally abused did not report for health facility care [96]. Our findings are also in keeping with a study that examine the experience of disabled women regarding respect during maternity care in the United Kingdom, the study concluded that the respondents were dissatisfied with the care provision characterized by physical abuses [97].

Lack of companionship, painful repeated virginal examinations and abandonment of women during labour was reported in this review to affect women psychologically and subsequently impede RMC. Also similar to another study done in Thailand which found out that women's experience of emotional loneliness during labour contributed to the negative maternal and childbirth outcomes [98].

Lack of privacy and confidential care during labour was also a factor that inhibit RMC found in this review. Women were not impressed and also feel embarrassed with the care they received because they were left uncovered exposing their genitalia, maintenance staff were present in the labour room which compromised their privacy. The maternity staff were also not adhering to confidential care. These impeded their decision for subsequent care. This finding conforms with another review where women reported disclosure of their sensitive information by the healthcare staff without their consent, their privacy were impaired during care [18].

\section{3) Strategies that would facilitate respectful maternity care}

Based on the papers reviewed, the strategies that would facilitate RMC target women, management and staff of maternity ward. Health education to pregnant women on what to expect during labour at antenatal period was found to enhance RMC. Adequate knowledge could reduce stress of explanation by midwives. A qualitative evidence synthesis of respectful care during delivery has affirmed health information provision to pregnant women at various level of maternity care would enhance RMC [99]. Similarly, an interventional study on how to mitigate disrespect and abuse during labour done in Tanzania reported an increased in women's knowledge about labour and delivery with associated minimal disrespect and abuse throughout childbirth [100].

Healthcare providers in this review suggested effective communication throughout delivery process would provide comfort and satisfaction to women during care. Evidence has shown that improving effective communication between pregnant women and healthcare staff would enhance RMC [101]. In addi- 
tion, study done in Tanga region, Tanzania, found effective communication reduced disrespect and abuse to women by $66 \%$ [102].

Capacity building of maternity healthcare staff on RMC including how to offer psychological support and handle hostile patients has proven to improve RMC. Evidence has shown training midwives on respectful and effective maternity care, and good rapport with women improves provision of dignified services [68] [79].

Staff are motivated by a good working environment, financial and non-financial benefits. It is evident that financial benefits and timely promotion can enhance nurses' work motivation which can enhance provision of RMC [103].

\section{4) Strengths}

Choosing qualitative studies was best for this review in view of the objectives which target studies that explore the experiences of women during labour, why and how healthcare staff mistreat women during delivery. We included studies from multiple respondents (women, maternity healthcare staff, husband) to have diverse experiences about the topic of this study and also to achieve triangulation of findings.

The robust and exhaustive literature search from multiple databases in this review provided optimal searches and guarantee adequate and efficient coverage of available studies. Screening of articles was independently conducted by two candidates and aimed at minimizing selection bias. Majority (91\%) of the included studies scored high (CASP score) with no study scored low.

\section{5) Limitations}

Despite ensuring quality review by following strict criteria, there may be possibility of some studies missed however this is unlikely because of robust and exhaustive literature searched. Considering the short duration for this review, if quantitative component was added it may have identified other enablers and barriers to RMC. About half (22) of the included studies for this review was from East African region, West Africa (10) and only six studies from Asia. Therefore, socio-cultural variations may vary between and within countries and may affect generalizability of findings.

\section{6) Implications for policy and practice}

This review showed that, women faced various forms of disrespect and abuses while seeking maternity care services and may deter them from facility-based care which can have an overall effect on the global target of reducing maternal and child mortality. These disrespect and abuses are due to lack of staff training on RMC services, attitude of the maternity care staff, health system failure among others.

Therefore, the following recommendations are made:

- Government/policy makers should provide an enabling environment for maternity healthcare staff by training on how to deliver effective RMC services including how to handle women and provide psycho-social support during labour, adequate manpower, financial and non-financial motivation. 
- Health workers should provide supportive environment for pregnant women by providing adequate information and involvement in decision during care, provision of health education to women on what to expect during labour.

- Families/communities should be oriented on how to respond and report any act of disrespect and abuse faced by women to the appropriate authorities in the existing systems.

\section{7) Implications for research}

The review focused on only qualitative studies in low and middle-income countries with few studies (six) from Asian continent. Therefore, more research is needed in all regions of low and middle-income countries for generalizability of findings and enables us to achieve global target of reducing maternal mortality. Review of quantitative studies also needed to know the burden of RMC in the region.

It would also be interested in future research to further explore reason why maternity healthcare staff not providing respectful maternity care for possible solution to the growing disrespect and abuse during maternity care services.

\section{Conclusion}

This review has highlighted various enablers and barriers to RMC. Good interpersonal relationship, privacy and confidential care facilitate positive experience. However, women faced different forms of barriers to receiving dignified care during maternity care ranging from provider behavioural barriers, working environmental constraints and health system challenges which affect health seeking behaviour. Such barriers could affect the global target of reducing maternal mortality especially in low and middle-income countries. Therefore, ensuring dignified and respectful care through capacity building of health workers on RMC, improving communication between women and workers, and improving working environment could contribute to an increase in health seeking bahaviors, consequently contributing to the reduction of maternal mortality.

\section{Conflicts of Interest}

The authors declare no conflicts of interest regarding the publication of this paper.

\section{References}

[1] United Nations Population Fund (2019) Trends in Maternal Mortality: 2000 to 2017.

https://www.unfpa.org/featured-publication/trends-maternal-mortality-2000-2017

[2] World Health Organization (2019) Maternal Mortality. https://www.who.int/news-room/fact-sheets/detail/maternal-mortality

[3] WHO (2019) World Health Organization: WHO, Causes of Child Mortality.

[4] Say, L., Chou, D., Gemmill, A., Tunçalp, Ö., Moller, A.-B., Daniels, J., Gülmezoglu, A.M., Temmerman, M. and Alkema, L. (2014) Global Causes of Maternal Death: A 
WHO Systematic Analysis. The Lancet Global Health, 2, e323-e333. https://doi.org/10.1016/S2214-109X(14)70227-X

[5] Okafor I.I., Ugwu, E.O. and Obi, S.N. (2015) Disrespect and Abuse during Facility-Based Childbirth in a Low-Income Country. International Journal of Gynecology \& Obstetrics, 128, 110-113. https://doi.org/10.1016/j.ijgo.2014.08.015

[6] Wassihun, B. and Zeleke, S. (2018) Compassionate and Respectful Maternity Care during Facility Based Child Birth and Women's Intent to Use Maternity Service in Bahir Dar, Ethiopia. BMC Pregnancy and Childbirth, 18, Article No. 294. https://doi.org/10.1186/s12884-018-1909-8

[7] World Health Organization (2016) WHO Recommendations on Antenatal Care for a Positive Pregnancy Experience. 196 p. https://www.who.int/publications/i/item/9789241549912

[8] Ndwiga, C., Warren, C.E., Ritter, J., Sripad, P. and Abuya, T. (2017) Exploring Provider Perspectives on Respectful Maternity Care in Kenya: "Work with What You Have". Reproductive Health, 14, Article No. 99. https://doi.org/10.1186/s12978-017-0364-8

[9] Bradley, S., McCourt, C., Rayment, J. and Parmar, D. (2016) Disrespectful Intrapartum Care during Facility-Based Delivery in Sub-Saharan Africa: A Qualitative Systematic Review and Thematic Synthesis of Women's Perceptions and Experiences. Social Science \& Medicine, 169, 157-170. https://doi.org/10.1016/j.socscimed.2016.09.039

[10] Mselle, L.T., Kohi, T.W. and Dol, J. (2018) Barriers and Facilitators to Humanizing Birth Care in Tanzania: Findings from Semi-Structured Interviews with Midwives and Obstetricians. Reproductive Health, 15, Article No. 137. https://doi.org/10.1186/s12978-018-0583-7

[11] Smith, J., Banay, R., Zimmerman, E., Caetano, V., Musheke, M. and Kamanga, A. (2020) Barriers to Provision of Respectful Maternity Care in Zambia: Results from a Qualitative Study through the Lens of Behavioral Science. BMC Pregnancy and Childbirth, 20, Article No. 26. https://doi.org/10.1186/s12884-019-2579-x

[12] Kruk, M.E., Kujawski, S., Mbaruku, G., Ramsey, K., Moyo, W. and Freedman, L.P. (2018) Disrespectful and Abusive Treatment during Facility Delivery in Tanzania: A Facility and Community Survey. Health Policy and Planning, 33, e26-e33. https://doi.org/10.1093/heapol/czu079

[13] Lefevre, A., Scott, K., Mohan, D., Shah, N., Bhatnagar, A., Labrique, A., Chamberlain, S., Dhar, D. and Ved, R. (2019) Development of a Phone Survey Tool to Measure Respectful Maternity Care During Pregnancy and Childbirth in India: Study Protocol. JMIR Research Protocols, 8, e12173. https://doi.org/10.2196/12173

[14] Snyder, H. (2019) Literature Review as a Research Methodology: An Overview and Guidelines. Journal of Business Research, 104, 333-339.

https://doi.org/10.1016/j.jbusres.2019.07.039

[15] Soilemezi, D. and Linceviciute, S. (2018) Synthesizing Qualitative Research: Reflections and Lessons Learnt by Two New Reviewers. International Journal of Qualitative Methods, 17, 1-14. https://doi.org/10.1177/1609406918768014

[16] Aveyard, H. (2019) Doing a Literature Review in Health and Social Care: A Practical Guide. 4th Edition, Open University Press, London.

[17] United Nations (2015) The Millennium Development Goals Report 2015.

[18] Ishola, F., Owolabi, O. and Filippi, V. (2017) Disrespect and Abuse of Women during Childbirth in Nigeria: A Systematic Review. PLoS ONE, 12, e0174084. 
https://doi.org/10.1371/journal.pone.0174084

[19] Bearman, M. and Dawson, P. (2013) Qualitative Synthesis and Systematic Review in Health Professions Education. Medical Education, 47, 252-260.

https://doi.org/10.1111/medu.12092

[20] Warren, C., Njuki, R., Abuya, T., Ndwiga, C., Maingi, G., Serwanga, J., Mbehero, F., Muteti, L., Njeru, A., Karanja, J., et al. (2013) Study Protocol for Promoting Respectful Maternity Care Initiative to Assess, Measure and Design Interventions to Reduce Disrespect and Abuse during Childbirth in Kenya. BMC Pregnancy and Childbirth, 13, Article No. 21. https://doi.org/10.1186/1471-2393-13-21

[21] Ith, P., Dawson, A. and Homer, C.S.E. (2013) Women's Perspective of Maternity Care in Cambodia. Women and Birth, 26, 71-75.

https://doi.org/10.1016/j.wombi.2012.05.002

[22] Bramer, W.M., Rethlefsen, M.L., Kleijnen, J. and Franco, O.H. (2017) Optimal Database Combinations for Literature Searches in Systematic Reviews: A Prospective Exploratory Study. Systematic Reviews, 6, Article No. 245.

https://doi.org/10.1186/s13643-017-0644-y

[23] Wright, K., Golder, S. and Lewis-Light, K. (2015) Erratum to: What Value Is the CINAHL Database When Searching for Systematic Reviews of Qualitative Studies? Systematic Reviews, 4, Article No. 169. https://doi.org/10.1186/s13643-015-0128-x

[24] Tawfik, G.M., Dila, K.A.S., Mohamed, M.Y.F., Tam, D.N.H., Kien, N.D., Ahmed, A.M. and Huy, N.T. (2019) A Step by Step Guide for Conducting a Systematic Review and Meta-Analysis with Simulation Data. Tropical Medicine and Health, 47, Article No. 46. https://doi.org/10.1186/s41182-019-0165-6

[25] Moher, D., Liberati, A., Tetzlaff, J., Altman, D.G. and The PRISMA Group (2010) Preferred Reporting Items for Systematic Reviews and Meta-Analyses: The PRISMA Statement. International Journal of Surgery, 8, 336-341. https://doi.org/10.1016/j.ijsu.2010.02.007

[26] Critical Appraisal Skills Programme (2018) CASP Qualitative Checklist.

[27] Harrison, J.K., Reid, J., Quinn, T.J. and Shenkin, S.D. (2017) Using Quality Assessment Tools to Critically Appraise Ageing Research: A Guide for Clinicians. Age and Ageing, 46, 359-365. https://doi.org/10.1093/ageing/afw223

[28] Kanavaki, A.M., Rushton, A., Klocke, R., Abhishek, A. and Duda, J.L. (2016) Barriers and Facilitators to Physical Activity in People with Hip or Knee Osteoarthritis: Protocol for a Systematic Review of Qualitative Evidence. BMJ Open, 6, e012049. https://doi.org/10.1136/bmjopen-2016-012049

[29] Thomas, J. and Harden, A. (2008) Methods for the Thematic Synthesis of Qualitative Research in Systematic Reviews. BMC Medical Research Methodology, 8, Article No. 45. https://doi.org/10.1186/1471-2288-8-45

[30] Chambers, L.A., Rueda, S., Baker, D.N., Wilson, M.G., Deutsch, R., Raeifar, E., Rourke, S.B. and The Stigma Review Team (2015) Stigma, HIV and Health: A Qualitative Synthesis. BMC Public Health, 15, Article No. 848. https://doi.org/10.1186/s12889-015-2197-0

[31] Kumbani, L.C., Chirwa, E., Malata, A., Odland, J.Ø. and Bjune, G. (2012) Do Malawian Women Critically Assess the Quality of Care? A Qualitative Study on Women's Perceptions of Perinatal Care at a District Hospital in Malawi. Reproductive Health, 9, Article No. 30. https://doi.org/10.1186/1742-4755-9-30

[32] Miltenburg, A.S., Lambermon, F., Hamelink, C. and Meguid, T. (2016) Maternity Care and Human Rights: What Do Women Think? BMC International Health and 
Human Rights, 16, Article No. 17. https://doi.org/10.1186/s12914-016-0091-1

[33] Afaya, A., Yakong, V.N., Afaya, R.A., Salia, S.M., Adatara, P., Kuug, A.K. and Nyande, F.K. (2017) A Qualitative Study on Women's Experiences of Intrapartum Care at Tamale Teaching Hospital, Ghana. Journal of Caring Sciences, 6, 303-314. https://doi.org/10.15171/jcs.2017.029

[34] Mgawadere, F., Smith, H., Asfaw, A., Lambert, J. and van den Broek, N. (2019) "There Is No Time for Knowing Each Other": Quality of Care during Childbirth in a Low Resource Setting. Midwifery, 75, 33-40. https://doi.org/10.1016/j.midw.2019.04.006

[35] De Kok, B.C., Uny, I., Immamura, M., Bell, J., Geddes, J. and Phoya, A. (2020) From Global Rights to Local Relationships: Exploring Disconnects in Respectful Maternity Care in Malawi. Qualitative Health Research, 30, 341-355. https://doi.org/10.1177/1049732319880538

[36] Ouédraogo, A., Kiemtoré, S., Zamané, H., Bonané, B.T., Akotionga, M. and Lankoande, J. (2014) Respectful Maternity Care in Three Health Facilities in Burkina Faso: The Experience of the Society of Gynaecologists and Obstetricians of Burkina Faso. International Journal of Gynecology \& Obstetrics, 127, S40-S42. https://doi.org/10.1016/j.ijgo.2014.07.009

[37] Yakubu, J., Benyas, D., Emil, S.V., Amekah, E., Adanu, R. and Moyer, C.A. (2014) It's for the Greater Good: Perspectives on Maltreatment during Labor and Delivery in Rural Ghana. Open Journal of Obstetrics and Gynecology, 4, 383-390. https://doi.org/10.4236/ojog.2014.47057

[38] Maputle, M.S. (2018) Support Provided by Midwives to Women during Labour in a Public Hospital, Limpopo Province, South Africa: A Participant Observation Study. BMC Pregnancy and Childbirth, 18, Article No. 210.

https://doi.org/10.1186/s12884-018-1860-8

[39] Afulani, P.A., Kirumbi, L. and Lyndon, A. (2017) What Makes or Mars the Facility-Based Childbirth Experience: Thematic Analysis of Women's Childbirth Experiences in Western Kenya. Reproductive Health, 14, Article No. 180. https://doi.org/10.1186/s12978-017-0446-7

[40] Ndirima, Z., Neuhann, F. and Beiersmann, C. (2018) Listening to Their Voices: Understanding Rural Women's Perceptions of Good Delivery Care at the Mibilizi District Hospital in Rwanda. BMC Women's Health, 18, Article No. 38. https://doi.org/10.1186/s12905-018-0530-3

[41] Duggan, R. and Adejumo, O. (2012) Adolescent Clients' Perceptions of Maternity Care in KwaZulu-Natal, South Africa. Women and Birth, 25, e62-e67. https://doi.org/10.1016/j.wombi.2011.10.004

[42] Lambert, J., Etsane, E., Bergh, A.-M., Pattinson, R. and Van den Broek, N. (2018) 'I Thought They Were Going to Handle Me Like a Queen but They Didn't': A Qualitative Study Exploring the Quality of Care Provided to Women at the Time of Birth. Midwifery, 62, 256-263. https://doi.org/10.1016/j.midw.2018.04.007

[43] Helelo, A.Z., Zungu, L.I. and Chiegil, R.J. (2015) What Creates Good Experiences for EmOC Clients in Public Health Facilities in Ethiopia? South African Family Practice, 57, 203-207. https://doi.org/10.1080/20786190.2015.1024014

[44] Sarkar, N.D.P., Bunders-Aelen, J. and Criel, B. (2018) The Complex Challenge of Providing Patient-Centred Perinatal Healthcare in Rural Uganda: A Qualitative Enquiry. Social Science \& Medicine, 205, 82-89. https://doi.org/10.1016/j.socscimed.2018.03.029

[45] Shimoda, K., Horiuchi, S., Leshabari, S. and Shimpuku, Y. (2018) Midwives' Respect 
and Disrespect of Women during Facility-Based Childbirth in Urban Tanzania: A Qualitative Study. Reproductive Health, 15, Article No. 8.

https://doi.org/10.1186/s12978-017-0447-6

[46] Madula, P., Kalembo, F.W., Yu, H. and Kaminga, A.C. (2018) Healthcare Provider-Patient Communication: A Qualitative Study of Women's Perceptions during Childbirth. Reproductive Health, 15, Article No. 135. https://doi.org/10.1186/s12978-018-0580-x

[47] Chadwick, R.J. (2019) Good Birth Narratives: Diverse South African Women's Perspectives. Midwifery, 77, 1-8. https://doi.org/10.1016/j.midw.2019.06.008

[48] Mselle, L.T., Kohi, T.W. and Dol, J. (2019) Humanizing Birth in Tanzania: A Qualitative Study on the (Mis)Treatment of Women during Childbirth from the Perspective of Mothers and Fathers. BMC Pregnancy and Childbirth, 19, Article No. 231. https://doi.org/10.1186/s12884-019-2385-5

[49] Khresheh, R., Barclay, L. and Shoqirat, N. (2019) Caring Behaviours by Midwives: Jordanian Women's Perceptions during Childbirth. Midwifery, 74, 1-5.

https://doi.org/10.1016/j.midw.2019.03.006

[50] Burrowes, S., Holcombe, S.J., Jara, D., Carter, D. and Smith, K. (2017) Midwives' and Patients' Perspectives on Disrespect and Abuse during Labor and Delivery Care in Ethiopia: A Qualitative Study. BMC Pregnancy and Childbirth, 17, Article No. 263. https://doi.org/10.1186/s12884-017-1442-1

[51] Millicent, D.V., Bemah, B.A., Emmanuel, N.K., Pascal, A., Jody, L.R. and Peter, D. (2019) Exploring Midwives' Understanding of Respectful and Non-Abusive Maternal Care in Kumasi, Ghana: Qualitative Inquiry. BioRxiv, 708776.

https://doi.org/10.1101/708776

[52] Ackers, L., Webster, H., Mugahi, R. and Namiiro, R. (2018) What Price a Welcome? Understanding Structure Agency in the Delivery of Respectful Midwifery Care in Uganda. International Journal of Health Governance, 23, 46-59. https://doi.org/10.1108/IJHG-11-2017-0061

[53] Kambala, C., Lohmann, J., Mazalale, J., Brenner, S., Sarker, M., Muula, A.S. and De Allegri, M. (2017) Perceptions of Quality across the Maternal Care Continuum in the Context of a Health Financing Intervention: Evidence from a Mixed Methods Study in Rural Malawi. BMC Health Services Research, 17, Article No. 392. https://doi.org/10.1186/s12913-017-2329-6

[54] Kyaddondo, D., Mugerwa, K., Byamugisha, J., Oladapo, O.T. and Bohren, M.A. (2017) Expectations and Needs of Ugandan Women for Improved Quality of Childbirth Care in Health Facilities: A Qualitative Study. International Journal of Gynecology \& Obstetrics, 139, 38-46. https://doi.org/10.1002/ijgo.12405

[55] Adinew, Y.M. and Assefa, N.A. (2017) Experience of Facility Based Childbirth in Rural Ethiopia: An Exploratory Study of Women's Perspective. Journal of Pregnancy, 2017, Article ID: 7938371. https://doi.org/10.1155/2017/7938371

[56] Maya, E.T., Adu-Bonsaffoh, K., Dako-Gyeke, P., Badzi, C., Vogel, J.P., Bohren, M.A. and Adanu, R. (2018) Women's Perspectives of Mistreatment during Childbirth at Health Facilities in Ghana: Findings from a Qualitative Study. Reproductive Health Matters, 26, 70-87. https://doi.org/10.1080/09688080.2018.1502020

[57] McMahon, S.A., George, A.S., Chebet, J.J., Mosha, I.H., Mpembeni, R.N. and Winch, P.J. (2014) Experiences of and Responses to Disrespectful Maternity Care and Abuse during Childbirth: A Qualitative Study with Women and Men in Morogoro Region, Tanzania. BMC Pregnancy and Childbirth, 14, Article No. 268. https://doi.org/10.1186/1471-2393-14-268 
[58] Chadwick, R.J., Cooper, D. and Harries, J. (2014) Narratives of Distress about Birth in South African Public Maternity Settings: A Qualitative Study. Midwifery, 30, 862-868. https://doi.org/10.1016/j.midw.2013.12.014

[59] Bohren, M.A., Vogel, J.P., Tunçalp, Ö., Fawole, B., Titiloye, M.A., Olutayo, A.O., Ogunlade, M., Oyeniran, A.A., Osunsan, O.R., Metiboba, L. Idris, H.A., Alu, F.E., Oladapo, O.T., Gülmezoglu, A.M. and Hindin, M.J. (2017) Mistreatment of Women during Childbirth in Abuja, Nigeria: A Qualitative Study on Perceptions and Experiences of Women and Healthcare Providers. Reproductive Health, 14, Article No. 9. https://doi.org/10.1186/s12978-016-0265-2

[60] Balde, M.D., Diallo, B.A., Bangoura, A., Sall, O., Soumah, A.M., Vogel, J.P. and Bohren, M.A. (2017) Perceptions and Experiences of the Mistreatment of Women during Childbirth in Health Facilities in Guinea: A Qualitative Study with Women and Service Providers. Reproductive Health, 14, Article No. 3.

https://doi.org/10.1186/s12978-016-0266-1

[61] Warren, C.E., Njue, R., Ndwiga, C. and Abuya, T. (2017) Manifestations and Drivers of Mistreatment of Women during Childbirth in Kenya: Implications for Measurement and Developing Interventions. BMC Pregnancy and Childbirth, 17, Article No. 102. https://doi.org/10.1186/s12884-017-1288-6

[62] Freedman, L.P., Kujawski, S.A., Mbuyita, S., Kuwawenaruwa, A., Kruk, M.E., Ramsey, K. and Mbaruku, G. (2018) Eye of the Beholder? Observation versus Self-Report in the Measurement of Disrespect and Abuse during Facility-Based Childbirth. Reproductive Health Matters, 26, 107-122. https://doi.org/10.1080/09688080.2018.1502024

[63] Malatji, R. and Madiba, S. (2020) Disrespect and Abuse Experienced by Women during Childbirth in Midwife-Led Obstetric Units in Tshwane District, South Africa: A Qualitative Study. International Journal of Environmental Research and Public Health, 17, 3667. https://doi.org/10.3390/ijerph17103667

[64] Orpin, J., Puthussery, S., Davidson, R. and Burden, B. (2018) Women's Experiences of Disrespect and Abuse in Maternity Care Facilities in Benue State, Nigeria. BMC Pregnancy and Childbirth, 18, Article No. 213.

https://doi.org/10.1186/s12884-018-1847-5

[65] Solnes, M.A., van Pelt, S., Meguid, T. and Sundby, J. (2018) Disrespect and Abuse in Maternity Care: Individual Consequences of Structural Violence. Reproductive Health Matters, 26, 88-106. https://doi.org/10.1080/09688080.2018.1502023

[66] Arnold, R., Van Teijlingen, E., Ryan, K. and Holloway, I. (2015) Understanding Afghan Healthcare Providers: A Qualitative Study of the Culture of Care in a Kabul Maternity Hospital. BJOG: An International Journal of Obstetrics \& Gynaecology, 122, 260-267. https://doi.org/10.1111/1471-0528.13179

[67] John, T.W., Mkoka, D.A., Frumence, G. and Goicolea, I. (2018) An Account for Barriers and Strategies in Fulfilling Women's Right to Quality Maternal Health Care: A Qualitative Study from Rural Tanzania. BMC Pregnancy and Childbirth, 18, Article No. 352. https://doi.org/10.1186/s12884-018-1990-Z

[68] Webber, G., Chirangi, B. and Magatti, N. (2018) Promoting Respectful Maternity Care in Rural Tanzania: Nurses' Experiences of the "Health Workers for Change" Program. BMC Health Services Research, 18, Article No. 658. https://doi.org/10.1186/s12913-018-3463-5

[69] Dullo, A.G., Hailemariam, N.W., Fulasa, T.B., Feyissa, D.W., Tessema, T.T., Debela, F.A. and Alamdo, A.G. (2019) Respectful Maternity Care: A Qualitative Study on the Experience of Health Providers in Public Health Facilities of North Shewa Zone, Oromia, Ethiopia. Ethiopian Journal of Reproductive Health, 11, 42-51. 
[70] Sudhinaraset, M., Treleaven, E., Melo, J., Singh, K. and Diamond-Smith, N. (2016) Women's Status and Experiences of Mistreatment during Childbirth in Uttar Pradesh: A Mixed Methods Study Using Cultural Health Capital Theory. BMC Pregnancy and Childbirth, 16, Article No. 332.

https://doi.org/10.1186/s12884-016-1124-4

[71] Mulenga, T., Moono, M., Mwendafilumba, M., Manasyan, A. and Sharma, A. (2018) Home Deliveries in the Capital: A Qualitative Exploration of Barriers to Institutional Deliveries in Peri-Urban Areas of Lusaka, Zambia. BMC Pregnancy and Childbirth, 18, Article No. 203. https://doi.org/10.1186/s12884-018-1837-7

[72] Sharma, G., Penn-Kekana, L., Halder, K. and Filippi, V. (2019) An Investigation into Mistreatment of Women during Labour and Childbirth in Maternity Care Facilities in Uttar Pradesh, India: A Mixed Methods Study. Reproductive Health, 16, Article No. 7. https://doi.org/10.1186/s12978-019-0668-y

[73] Rosen, H.E., Lynam, P.F., Carr, C., Reis, V., Ricca, J., Bazant, E.S. and Bartlett, L.A. (2015) Direct Observation of Respectful Maternity Care in Five Countries: A Cross-Sectional Study of Health Facilities in East and Southern Africa. BMC Pregnancy and Childbirth, 15, Article No. 306. https://doi.org/10.1186/s12884-015-0728-4

[74] Rominski, S.D., Lori, J., Nakua, E., Dzomeku, V. and Moyer, C.A. (2017) When the Baby Remains There for a Long Time, It Is Going to Die so You Have to Hit Her Small for the Baby to Come Out: Justification of Disrespectful and Abusive Care during Childbirth among Midwifery Students in Ghana. Health Policy and Planning, 32, 215-224. https://doi.org/10.1093/heapol/czw114

[75] Afulani, P.A., Buback, L., Kelly, A.M., Kirumbi, L., Cohen, C.R. and Lyndon, A. (2020) Providers' Perceptions of Communication and Women's Autonomy during Childbirth: A Mixed Methods Study in Kenya. Reproductive Health, 17, Article No. 85. https://doi.org/10.1186/s12978-020-0909-0

[76] Shiferaw, S., Spigt, M., Godefrooij, M., Melkamu, Y. and Tekie, M. (2013) Why Do Women Prefer Home Births in Ethiopia? BMC Pregnancy and Childbirth, 13, Article No. 5. https://doi.org/10.1186/1471-2393-13-5

[77] Gebremichael, M.W., Worku, A., Medhanyie, A.A., Edin, K. and Berhane, Y. (2018) Women Suffer More from Disrespectful and Abusive Care than from the Labour Pain Itself: A Qualitative Study from Women's Perspective. BMC Pregnancy and Childbirth, 18, Article No. 392. https://doi.org/10.1186/s12884-018-2026-4

[78] Kanengoni, B., Andajani-Sutjahjo, S. and Holroyd, E. (2019) Women's Experiences of Disrespectful and Abusive Maternal Health Care in a Low Resource Rural Setting in Eastern Zimbabwe. Midwifery, 76, 125-131.

https://doi.org/10.1016/j.midw.2019.06.003

[79] Orpin, J., Puthussery, S. and Burden, B. (2019) Healthcare Providers' Perspectives of Disrespect and Abuse in Maternity Care Facilities in Nigeria: A Qualitative Study. International Journal of Public Health, 64, 1291-1299.

https://doi.org/10.1007/s00038-019-01306-0

[80] Moridi, M., Pazandeh, F., Hajian, S. and Potrata, B. (2020) Midwives' Perspectives of Respectful Maternity Care during Childbirth: A Qualitative Study. PLoS ONE, 15, e0229941. https://doi.org/10.1371/journal.pone.0229941

[81] Merriel, A., Hussein, J., Malata, A., Coomarasamy, A. and Larkin, M. (2018) Learning from the Experience of Maternity Healthcare Workers in Malawi: A Qualitative Study Leading to Ten Low-Cost Recommendations to Improve Working Lives and Quality of Care. BMC Pregnancy and Childbirth, 18, Article No. 336. 
https://doi.org/10.1186/s12884-018-1960-5

[82] Jolly, Y., Aminu, M., Mgawadere, F. and Van den Broek, N. (2019) "We Are the Ones Who Should Make the Decision"-Knowledge and Understanding of the Rights-Based Approach to Maternity Care among Women and Healthcare Providers. BMC Pregnancy and Childbirth, 19, Article No. 42. https://doi.org/10.1186/s12884-019-2189-7

[83] Srivastava, A., Avan, B.I., Rajbangshi, P. and Bhattacharyya, S. (2015) Determinants of Women's Satisfaction with Maternal Health Care: A Review of Literature from Developing Countries. BMC Pregnancy and Childbirth, 15, Article No. 97. https://doi.org/10.1186/s12884-015-0525-0

[84] Baas, C.I., Erwich, J.J.H.M., Wiegers, T.A., De Cock, T.P. and Hutton, E.K. (2015) Women's Suggestions for Improving Midwifery Care in the Netherlands. Birth, 42, 369-378. https://doi.org/10.1111/birt.12185

[85] World Health Organization (2018) WHO: Recommendation on Effective Communication between Maternity Care Providers and Women in Labour | RHL.

[86] Vilamovska, A.-M. (2010) Improving the Quality and Cost of Healthcare Delivery: The Potential of Radio Frequency Identification (RFID) Technology. The Pardee RAND Graduate School, RAND Corporation, Santa Monica.

[87] World Health Organization (2018) WHO Recommendation on Respectful Maternity Care during Labour and Childbirth | RHL.

[88] Downe, S., Lawrie, T.A., Finlayson, K. and Oladapo, O.T. (2018) Effectiveness of Respectful Care Policies for Women Using Routine Intrapartum Services: A Systematic Review. Reproductive Health, 15, Article No. 23.

https://doi.org/10.1186/s12978-018-0466-y

[89] Shaw, D., Guise, J.-M., Shah, N., Gemzell-Danielsson, K., Joseph, K., Levy, B., Wong, F., Woodd, S. and Main, E.K. (2016) Drivers of Maternity Care in High-Income Countries: Can Health Systems Support Woman-Centred Care? The Lancet, 388, 2282-2295. https://doi.org/10.1016/S0140-6736(16)31527-6

[90] Nagahama, E.E. and Santiago, S.M. (2008) Childbirth Practices and Challenges for Humanization of Care in Two Public Hospitals in Southern Brazil. Cadernos de Saúde Pública, 24, 1859-1868. https://doi.org/10.1590/S0102-311X2008000800014

[91] Montesinos-Segura, R., Urrunaga-Pastor, D., Mendoza-Chuctaya, G., Taype-Rondan, A., Helguero-Santin, L.M., Martinez-Ninanqui, F.W., Centeno, D.L., Jiménez-Meza, Y., Taminche-Canayo, R.C. and Paucar-Tito, L. (2018) Disrespect and Abuse during Childbirth in Fourteen Hospitals in Nine Cities of Peru. International Journal of Gynecology \& Obstetrics, 140, 184-190. https://doi.org/10.1002/ijgo.12353

[92] White Ribbon Alliance for Safe Motherhood (2011) Respectful Maternity Care, The Universal Rights of Childbearing Women.

[93] White Ribbon Alliance (2020) Respectful Maternity Care Charter: Universal Rights of Mothers and Newborns.

[94] Simons, A.M.W., Houkes, I., Koster, A., Groffen, D.A.I. and Bosma, H. (2018) The Silent Burden of Stigmatisation: A Qualitative Study among Dutch People with a Low Socioeconomic Position. BMC Public Health, 18, Article No. 443. https://doi.org/10.1186/s12889-018-5210-6

[95] Beck, C.T. (2018) A Secondary Analysis of Mistreatment of Women during Childbirth in Health Care Facilities. Journal of Obstetric, Gynecologic \& Neonatal Nursing, 47, 94-104. https://doi.org/10.1016/j.jogn.2016.08.015

[96] Grilo Diniz, C.S., Rattner, D., Lucas d'Oliveira, A.F.P., De Aguiar, J.M. and Niy, 
D.Y. (2018) Disrespect and Abuse in Childbirth in Brazil: Social Activism, Public Policies and Providers' Training. Reproductive Health Matters, 26, 19-35. https://doi.org/10.1080/09688080.2018.1502019

[97] Hall, J., Hundley, V., Collins, B. and Ireland, J. (2018) Dignity and Respect during Pregnancy and Childbirth: A Survey of the Experience of Disabled Women. BMC Pregnancy and Childbirth, 18, Article No. 328. https://doi.org/10.1186/s12884-018-1950-7

[98] Siriwan Yuenyong, R., Veena Jirapaet, R. and O’Brien, B.A. (2008) Support from a Close Female Relative in Labour: The Ideal Maternity Nursing Intervention in Thailand. Journal of the Medical Association of Thailand, 91, 253-260.

[99] Shakibazadeh, E., Namadian, M., Bohren, M.A., Vogel, J.P., Rashidian, A., Nogueira Pileggi, V., Madeira, S., Leathersich, S., Tunçalp, Ö., Oladapo, O.T., et al. (2018) Respectful Care during Childbirth in Health Facilities Globally: A Qualitative Evidence Synthesis. BJOG: An International Journal of Obstetrics \& Gynaecology, 125, 932-942. https://doi.org/10.1111/1471-0528.15015

[100] Ratcliffe, H.L., Sando, D., Lyatuu, G.W., Emil, F., Mwanyika-Sando, M., Chalamilla, G., Langer, A. and McDonald, K.P. (2016) Mitigating Disrespect and Abuse during Childbirth in Tanzania: An Exploratory Study of the Effects of Two Facility-Based Interventions in a Large Public Hospital. Reproductive Health, 13, Article No. 79. https://doi.org/10.1186/s12978-016-0187-z

[101] Rowe, R.E., Garcia, J., Macfarlane, A. and Davidson, L. (2002) Improving Communication between Health Professionals and Women in Maternity Care: A Structured Review. Health Expectations. An International Journal of Public Participation in Health Care and Health Policy, 5, 63-83. https://doi.org/10.1046/j.1369-6513.2002.00159.x

[102] Kujawski, S.A., Freedman, L.P., Ramsey, K., Mbaruku, G., Mbuyita, S., Moyo, W. and Kruk, M.E. (2017) Community and Health System Intervention to Reduce Disrespect and Abuse during Childbirth in Tanga Region, Tanzania: A Comparative Before-and-After Study. PLoS Medine, 14, e1002341.

https://doi.org/10.1371/journal.pmed.1002341

[103] Baljoon, R.A., Banjar, H.E. and Banakhar, M.A. (2018) Nurses' Work Motivation and the Factors Affecting It: A Scoping Review. International Journal of Nursing \& Clinical Practices, 5, Article No. 5. https://doi.org/10.15344/2394-4978/2018/277 